\title{
Síndrome de Klippel-Feil asociado a deformidad de Sprengel y escoliosis
}

\author{
Klippel-Feil syndrome associated with Sprengel deformity and scoliosis \\ Luis Gerardo Domínguez Carrillo, * Luis Gerardo Domínguez Gasca ${ }^{\ddagger}$ \\ Citar como: Domínguez CLG, Domínguez GLG. Síndrome de Klippel-Feil asociado a deformidad de \\ Sprengel y escoliosis. Acta Med. 2020; 18 (4): 431-432. https://dx.doi.org/10.35366/97276
}

Paciente masculino de 24 años, comerciante, que acude a consulta por presentar irradiación cara externa de brazo izquierdo posterior a choque por alcance, con mecanismo de latigazo 24 horas antes. A la exploración física, paciente con talla de $1.60 \mathrm{~m}$, peso $60 \mathrm{k}$, IMC de 23.4; TA 120/70 mmHg; FC $90 \mathrm{l} / \mathrm{min}$; FR $18 \mathrm{r} / \mathrm{min}$; Temp. y $36.5^{\circ} \mathrm{C}$. Marcha normal, cráneo con implantación baja de cabello; cara y pares craneales sin alteraciones; cuello corto, con posición de flexión lateral a la izquierda, con limitación importante de movilidad alcanzando $30^{\circ}$ de flexo-extensión, y $35^{\circ}$ de rotación en ambos sentidos; tórax corto con asimetría de cintura escapular por presencia de escoliosis dorsal izquierda y lumbar derecha, hombro y escápula izquierda elevados; miembros torácicos simétricos con arcos de movilidad completos, examen clínico muscular normal, sensibilidad con parestesias e hiperestesia en territorio C5 izquierdo; examen clínico muscular con calificación 5/5 de manera global, reflejos osteotendinosos bicipital, radial y estilorradial normales al igual que llenado capilar; abdomen y extremidades pélvicas normales. Por las características fenotípicas del paciente y las alteraciones esqueléticas observadas se efectúan los diagnósticos de: a) síndrome de Klippel-Feil asociado a escoliosis y deformidad de Sprengel, b) cervicalgia con irritación radicular C5 izquierda secundario a lesión en latigazo de 24 horas de evolución. Se solicitan radiografías antero-posterior y lateral de columna cervical, confirmando presencia de fusión vertebral de columna cervical en tres bloques, el superior por C2-C3, el intermedio por C4-C5, y el inferior por C6-C7. Además de escoliosis cervical derecha, escoliosis torácica izquierda con deformidad costal separando arcos costales izquierdos y reduciendo espacios intercostales derechos (Figura 1). Se coloca collarín cervical no convencional manufacturado con algodón y venda prescribiendo su uso por cinco días con retiro paulatino, se prescribió meloxicam a dosis de 15 mg/día por 10 días y paracetamol a dosis de 500 mg TID; se cita a revaloración en cinco días, de persistir manifestaciones de irritación de la raíz C5 izquierda se derivará con resonancia magnética a neurocirugía.

El síndrome de Klippel-Feil (SKF) constituye una alteración esquelética caracterizada por la fusión congénita de dos o más vértebras cervicales. La tríada clínica clásica consiste en cuello corto, implantación baja del cabello y limitación para los movimientos del cuello. ${ }^{1}$ Existe una inadecuada segmentación de las vértebras durante la cuarta semana de gestación, las mutaciones asociadas se localizan en los loci del gen GDF3 (cromosoma 12p13.31), GDF6 (cromosoma 8q22.1) y MEOX12 (cromosoma 17q21.31). La alteración de éstos durante la cuarta semana de desarrollo embrionario produce anormalidad en la diferenciación de somitas, donde las células de la porción ventral o esclerotomo expresan el factor de transcripción Pax1, el cual inicia la cascada de genes que forman el cartílago y hueso para la formación de vértebras, costillas y esternón. Su incidencia estimada es de 1/40,000 nacimientos, es más frecuente en el género femenino con relación de 1.5/:1. ${ }^{3}$ Tiene carácter autosómico dominante con expresión variable, existen reportes de herencia autosómica recesiva ${ }^{4}$ y casos esporádicos por mutación de novo. El SKF ha sido descrito como una manifestación del síndrome alcohólico

\footnotetext{
* Especialista en Medicina de Rehabilitación. Catedrático de la Facultad de Medicina de León, Universidad de Guanajuato, México.

‡ Ortopedista. División de cirugía del Hospital Ángeles León. León, Guanajuato, México.
}

Correspondencia:

Acad. Dr. Luis Gerardo Domínguez Carrillo

Correo electrónico: Igdomínguez@hotmail.com

Aceptado: 12-12-2019.

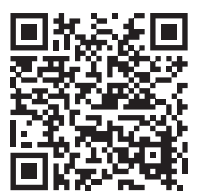



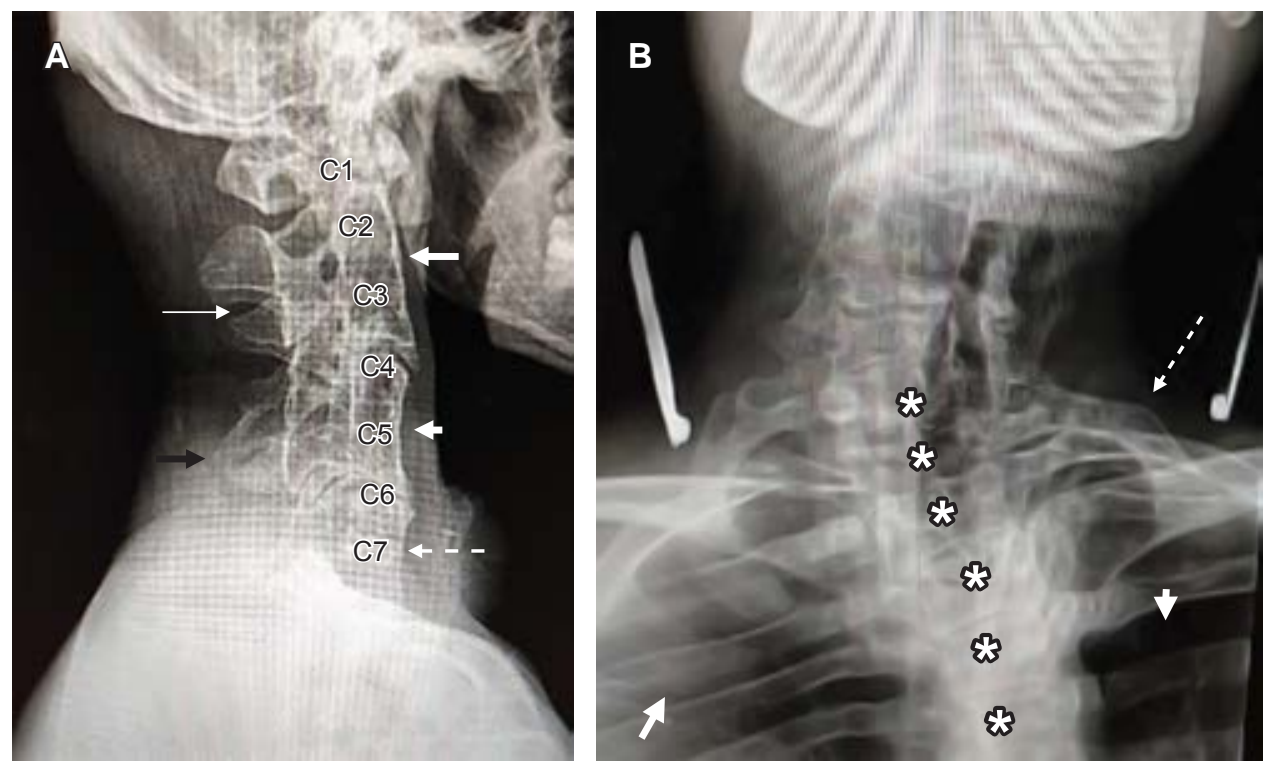

Figura 1: A) Imagen radiográfica lateral de columna cervical que muestra fusión de la misma en tres bloques, el superior conformado por C2-C3 (flecha blanca), el medio por C4-C5 (cabeza de flecha) y el inferior por C6-C7 (flecha punteada), con fusión de arcos posteriores C2-C3 (flecha delgada) y C4-C5 (flecha negra). B) escoliosis cervical derecha y torácica izquierda (asteriscos); elevación y deformidad de primer arco costal con elevación de hemicintura escapular izquierda, separación de espacios intercostales izquierdos (cabeza de flecha) y disminución de espacios intercostales derechos (flecha blanca) correspondiendo a síndrome de Klippel Feil asociado a deformidad de Sprengel y escoliosis en masculino de 24 años.

fetal y un fenotipo similar se ha evidenciado ante el tratamiento materno con ácido valproico -clínicamente se ha reportado con asociación con otras alteraciones como a) afonía y/o disfonía en 35\% de los casos por malformación de los cartílagos laríngeos; ${ }^{5}$ b) deformidad de Sprengel en $50 \%$ de los casos (escápula anormalmente alta como en el caso presentado); c) alteraciones auditivas, ya sea neurosensorial o mixta en $30 \%$ de los pacientes, principalmente femeninos; d) escoliosis y cifosis en $60 \%$ de los individuos; malformaciones del sistema urinario en 35\%; e) asimetría facial y cuello alado en $20 \%$ de los casos; y f) malformaciones cardiacas entre 4.2 y 14\%, las más frecuentes son los defectos del tabique interventricular seguidos de la coartación aórtica.

Por lo general el SKF no se asocia por sí mismo a cervicalgia, por lo que ante situaciones traumáticas de cuello resulta relevante para el neurocirujano, el ortopedista y el especialista en medicina de rehabilitación, pues la anatomía está alterada y tanto el diagnóstico como el manejo pueden resultar complejos.

\section{REFERENCIAS}

1. Samartzis D, Kalluri P, Herman J, Lubicky JP, Shen FH. "Clinical triad" findings in pediatric Klippel-Feil patients. Scoliosis Spinal Disord. 2016; 11: 15-16.

2. Mohamed JY, Faqeih E, Alsiddiky A, Alshammari MJ, Ibrahim NA, Alkuraya FS. Mutations in MEOX1, encoding mesenchyme homeobox 1, cause Klippel-Feil anomaly. Am J Hum Genet. 2013; 92: 157-161.

3. Gruber J, Saleh A, Bakhsh W, Rubery PT, Mesfin A. The prevalence of Klippel-Feil syndrome: a computed tomography-based analysis of 2,917 patients. Spine Deform. 2018; 6: 448-453.

4. Karaca E, Yuregir OO, Bozdogan ST, Aslan H, Pehlivan D, Jhangiani $\mathrm{SN}$ et al. Rare variants in the notch signaling pathway describe a novel type of autosomal recessive Klippel-Feil syndrome. Am J Med Genet A. 2015; 167A: 2795-2799.

5. Kenna MA, Irace AL, Strychowsky JE, Kawai K et al. Otolaryngologic manifestations of Klippel-Feil syndrome in children. JAMA Otolaryngol Head Neck Surg. 2018; 144: 238-243. 